\title{
Making Leaders' and Followers' Relationship Sustainable: The Impact of Leaders' Behavioral Integrity on Employees' Voice in the Banking Sector of Pakistan
}

\author{
Mubasher Javed ${ }^{1}$, Amna Niazi ${ }^{2, *}$, Yasuo Hoshino $\left.{ }^{3}{ }^{(}\right)$, Hamid Hassan $^{4}$ and Mujahid Hussain ${ }^{4}$ \\ 1 Institute of Business \& Management, University of Engineering \& Technology, Lahore 54770, Pakistan; \\ mubasher.javeed@gmail.com \\ 2 Humanities and Management Sciences Department, University of Engineering \& Technology, \\ Lahore 54770, Pakistan \\ 3 Institute of Policy and Planning Sciences, University of Tsukuba, 1-1-1 Tennodai, \\ Tsukuba Shi 305-8573, Ibaraki, Japan; hoshino2003@gmail.com \\ 4 FAST School of Management, National University of Computer \& Emerging Sciences, Lahore 54770, Pakistan; \\ hamid.hassan@nu.edu.pk (H.H.); mujahid.hussain@nu.edu.pk (M.H.) \\ * Correspondence: amna.niazi@uet.edu.pk
}

\section{check for}

updates

Citation: Javed, M.; Niazi, A.; Hoshino, Y.; Hassan, H.; Hussain, M. Making Leaders' and Followers' Relationship Sustainable: The Impact of Leaders' Behavioral Integrity on Employees' Voice in the Banking Sector of Pakistan. Sustainability 2021, 13, 11733. https://doi.org/ $10.3390 /$ su132111733

Academic Editors: Yoshiki Shimomura and Shigeru Hosono

Received: 28 September 2021

Accepted: 18 October 2021

Published: 23 October 2021

Publisher's Note: MDPI stays neutra with regard to jurisdictional claims in published maps and institutional affiliations.

Copyright: (c) 2021 by the authors. Licensee MDPI, Basel, Switzerland. This article is an open access article distributed under the terms and conditions of the Creative Commons Attribution (CC BY) license (https:/ / creativecommons.org/licenses/by/ $4.0 /)$.

\begin{abstract}
The behavioural integrity of leaders is not only an individual trait that can earn them respect in their personal capacity, but it also may positively affect their followers and ultimately improve the organization's effectiveness in a variety of ways. The relationship between behavioural integrity and employees using their voice has been studied by researchers through multiple aspects. This study brings a new perspective in this discussion by investigating the effect of leaders' behavioural integrity on employees' voice both directly and through the mediating roles of psychological safety and trust in the leader. The cross-sectional data of 384 employees collected from the banking sector in Pakistan is used to shed light on this new perspective in the relationship between the behavioural integrity of a leader and employees' comportment in using their voice. The results of the empirical analyses support the direct effect of the behavioural integrity of leaders on employees' voice. A significant mediating role of psychological safety and trust is also supported in the empirical analyses. The findings of the study bear important implications for leaders and business managers working in companies by providing insight on the importance of behavioural integrity of leaders in encouraging employees to have a voice in organizations.
\end{abstract}

Keywords: leaders' behavioural integrity; psychological safety; trust in leader; employees' voice; leadership

\section{Introduction}

Ethical issues and their consequences are under the spotlight of research nowadays. Several attempts in this regard have tried examining the causes of deviation from the path of integrity by leaders and the reluctance of subordinates to raise their voices against it. It goes without saying that the integrity of a leader can play a vital role in the success of an organization. Meanwhile, the relationship between a leader's behavioural integrity (BI) and employees' voice (EV) has not drawn much attention in the organizational behaviour literature [1]. Vigilant employees with the willingness and courage to raise their voice when needed can help to keep organizations on the right track [1]. However, employees often feel unsafe to raise their voice because it is considered to be a risky behavior in the face of status quo forces and the power-wielders who shape the prevalent frameworks of thought and routine [2]. Raising a voice against the status quo and challenging the power-wielders is, therefore, not a common behavior among employees [3]. Likewise, such behavior may carry a high personal cost for employees, which can make them scared of speaking up. This suggests that to give employees a voice is to induce employees to 
perceive psychological safety (PS) in the face of such fears. Another factor that can facilitate $\mathrm{EV}$ is the trust of employees in a leader [4]. Employees may feel encouraged to raise their voice in the best interest of the community or organization if they have a high level of trust in their leaders. Among several definitions of trust, the common perspective is that trust is the readiness to be vulnerable towards the actions of others with a hope that others will perform specific actions that are vital to the one who trusts, regardless of the capacity to control or exploit the others [4]. Consequently, this study uses the ideas of psychological safety and trust in leaders (TILs) as factors mediating the relationship between BI and EV. Therefore, this research aims to investigate:

(1) The direct effects of leaders' BI on EV;

(2) The direct effects of leaders' BI on psychological safety;

(3) The direct effects of leaders' BI on trust in leaders;

(4) The direct effects of psychological safety on EV;

(5) The direct effects of trust in leaders on EV;

(6) The effect of psychological safety in mediating between a leader's BI and EV;

(7) The effect of trust in the leader in mediating between a leader's BI and EV.

The data used in the study were obtained from the banking sector in an emerging economy. The study contributes both practical and theoretical implications by applying social exchange theory to clarify the important aspects of high BI in encouraging EV in organizations. Additionally, the mediation roles of psychological safety and TILs in the relationship between $\mathrm{BI}$ of leaders and $\mathrm{EV}$ is explored.

\subsection{Behavioral Integrity}

BI is defined as the uniformity of an entity's actions and words. It can also be termed as keeping promises and an assurance of 'walking the talk' [3]. It involves the perceived fit between enacted and supported values and also the certainty of keeping promises. Simons (2002) argued that maintaining one's behavioural integrity is not just as simple as being conscientious but also requires the communication skills to convey it and minimize misunderstandings so that others will comprehend it as such [2].

Integrity is considered to be a key ingredient for leadership $[5,6]$. According to Simons (2002), BI is a sub-element of integrity and is defined as the perceived pattern of alignment between words and actions of an entity, as well as the tendency to keep promises and display the espoused values. He also explains that $\mathrm{BI}$ is the alignment between words and behaviour but it may not be a test of the morality of a leader. This means that regardless of the morality of the principle, fulfilling promises, and the disposition of espoused values are included in a leader's BI [2]. Similarly, Palanski and Yammarino (2007) define BI as the consistency of an entity's words and actions [7]. They categorize integrity into five main components: uniformity of words and actions, totality, reliability in adversity, moral behaviour, and being true to oneself. As per the definition of Simons (2002), BI is recognized as a subjective quality and is dependent on the discretion of an individual regarding how to perceive the matching of words and actions [2]. Thus, it is plausible to note that a leader's BI may have a significant impact on several aspects within an organization including employees' capacity and willingness to raise their voices i.e., EV. On the other hand, EV is an important aspect to focus on because it contributes to several important areas, such as learning, organizational development, the fruitful execution of novel practices, and ethical decision making [8]. Past studies have also explored the effects of EV on commitment, goodwill, motivation, and work engagement, etc. This study proposes that there is an interesting relationship between BI and EV [9], directly, as well as through mediating factors of employees' PS and TIL.

\subsection{Employees' Voice}

During the 1990s, organizational behaviour scholars began to work on narrowed aspects of the concept of voice; for instance, McCabe and Lewin (1992) added the concept of participation in EV along with grievances [10]. Later, Van Dyne and LePine (1998) 
defined it as an extra role behaviour that stresses the expression of positive challenge with the intent to improve rather than to criticize [11]. These definitions were then analysed and integrated by Morrison (2014) who defines EV as voluntary and informal communication by workforce about ideas, recommendations, apprehensions, problems, and views about people who have the authority with the motive to bring positive change [12].

From the above discussion we can synthesize that EV has four main ingredients. Firstly, this behaviour is voluntary, and is completely dependent on employees. Secondly, it is concerned with context, as it contains an aim to improve or bring change. Thirdly, the one who is raising voice has no authority to execute a proposal or solve an issue; rather, it can only raise voice in front of those having the authority. Fourthly, this behaviour suggests an honest and blunt communication between employees and their supervisors.

\subsection{Behavioral Integrity (BI) and Employees' Voice (EV)}

Even though leaders' BI impacts the behaviours and attitudes of followers, past studies rarely linked it with EV [13]. The integrity of leaders has been said to be the foundation of the manners and ethical environment of an organization [14]. Leaders send strong signals to their employees about their morals through their actions, which is known as role modelling [15]. Numerous researchers and managers accept the fact that leadership without integrity may harm the organizations because the behaviour of those who have authority is the vital component to determine the ethical environment of the workplace as a whole [16].

It is plausible to conclude from above discussion that BI of a leader can play a significant role in shaping the attitudes of employees towards the organization. EV being an important aspect of employees' attitude is bound to become affected by the BI of a leader [12]. Since 1980s, EV has attained much attention from the researchers in the field of Organizational Behavior (OB) and Human Resource Management (HRM). In OB, it is closely linked with the organizational development (OD) while in HRM it is treated as one of the basic democratic right of the workers to express their opinions [17]. From employees' perspective, willingness to take risk and honesty are required for EV in a workplace [18]. Leaders can encourage and inspire employees to voice their opinions and concerns [4]. Past studies have indicated that leaders' high integrity and selflessness towards employees is necessary to develop a culture in which employees do not feel reluctant to express their thoughts [19].

When employees try to take initiative and try to bring some change, they need to channelize and share their suggestions to someone who has the authority to act [20]. Thus leaders are supposed to be the targets for employees' voice behaviors because they possess the authority over crucial consequences, such as performance appraisals [21]. It is possible that a leader may take voice behaviour as fault-finding and ultimately tag the employee as negative or unreliable. Hence, even though voice behaviour might result towards improvements and exhibit an employee's ability or innovativeness, it can also potentially annoy the leaders [13]. Therefore, employees can be confused about response of their managers towards suggestions and may consider voice behaviour as dangerous and risky. In this context, leaders' BI can help employees to decide about voice behaviour. With high BI, leaders can create an atmosphere of trust which will ultimately induce employees to raise their voices in the best interest of the organization without any fear of being misunderstood as negative or fault-finding [15]. A good match between words and actions of leaders will send message to followers regarding reliability and trustworthiness of leaders. A mismatch on the other hand will create the lack of trust and fear of being penalized in case of raising one's voice [2]. Apart from the alignment of words and actions, better communication by leaders to express themselves also plays an important role. In recent studies, researchers have found that clear communication by leaders helps to increase voice behaviour [9].

A consistent alignment of words and actions by the leader sends a strong message to followers regarding the expectation of preferred behavioural pattern from them. Consequently, there can be a significant improvement in the hesitation to raise voice and 
confusion of their role as members of organization making it easy for them to meet the expectations of their managers [13]. On similar lines, earlier researches have shown that the feelings of ambiguity negatively impact EV behaviour [19]. The credibility of the leader is at serious stake when it is unable to walk the talk. On the other hand followers working under a leader with high level of BI are more likely to feel safe and comfortable in raising their voice [13]. The above discussion leads us to following hypothesis:

\section{Hypothesis 1 (H1). Leaders' BI will have a direct positive relationship with EV.}

\subsection{Psychological Safety (PS)}

The term 'psychological safety' is defined as a safe interpersonal environment for employees [22]. PS has been discussed in the literature regarding work environment [23]. These endeavours have yielded several definitions of PS with slight difference. However, the majority of past scholars agree on the definition of Edmondson (1999), which defines PS as a general belief among members of a team that it is safe in work environment to take interpersonal risk [1]. As it is clear from the definition, Edmondson (1999) also gives a new direction to PS as related to team level instead of individual level. Furthermore, the explanation of Edmondson (1999) refers to PS as the belief of workers that their contemporaries are not going to dislike them for being who they are, what their thoughts and views are, and they expect to have respect for the abilities of each other as people have interest in one another and have good intentions to positively contribute and take risks without negative conflicts [1]. While the concept of PS has some overlapping with the concept of trust, the PS is, however, distinguished from trust as it focuses on how group norms are perceived by the members, while the focus of trust is on how an individual or a group is viewed by others.

On the dependent side, EV also aims at introducing change, thus creating disruptive forces which challenge the organizational status quo. EV therefore demands that employees should be able to convince others to acknowledge new ideas, which may be viewed as a challenge to authority and harm to benefits of other people [18]. Failing which, employees may suffer from backfire such as loss of promotion and other career opportunities. Because the likely targets of EV have coercive and reward powers, the uncertainties and fear of losses are likely to keep employees silent [18]. Not all organizations specifically define their environment; therefore, the consequences of EV may be unclear, particularly in politicized organizations, where leaders follow a self-serving style [24]. Because the rules about coercive and rewards powers may change frequently in unpredictable and volatile environments, employees may lose confidence that their voice will lead to positive outcomes [24]. The behaviour-outcome relationship, therefore, becomes a "black box" having incomplete information. This situation may lead employees to perceive a high risk in honest communication. In the light of social exchange theory, leaders' BI may remove uncertainty in terms of the relationship between performance and rewards and may result in psychological safety that will lead to effective EV. Peng and Wei (2019) after studying the direct link between BI and EV also emphasized the importance of examining the mediating effects of psychological safety in this relationship [13]. To examine Leaders' BI within a theoretical framework considering an underlying process through which leaders' BI affects EV, we draw on the mediating role of psychological safety in this relationship. It is proposed that the mediation model would enhance the originality of the study, especially in the context of the data used for this study. The hypotheses for mediation model with PS as mediator are presented as below:

Hypothesis 2 (H2). Leader's BI will have a direct positive relationship with Psychological Safety.

Hypothesis 3 (H3). Psychological Safety will have a direct positive relationship with EV.

Hypothesis 4 (H4). Psychological Safety is a mediator between Leader's BI and EV. 


\subsection{Trust in Leader}

Among several definitions of trust, the consensus is that trust is the readiness to be vulnerable towards the actions of others with a hope that others will perform specific actions that are vital to the one who trusts, regardless of the capacity to control or exploit the others [4]. This definition presents trust as a concept based on two entities. i.e., a trusting one (Trustor) and a trusted one (Trustee).

A thorough research of previous studies shows that trust is discussed at two levels, i.e., the interpersonal level and the team level. The initial work adopted a sociological view, according to which, trust involves overall views and behaviours about the extent to which others are likely to be dependable and supportive. Later studies focused on a psychological perspective; according to this view, trust is a psychological state or orientation of trustor toward the trustee with whom the actor is in some way inter-reliant to attain valued outcomes or resources [25]. The concept was then extended to teams by defining the difference at the team level. At team level, both trustors and trustees comprise multiple members [26]. In this study, the trust is used at an interpersonal level as it is considered to be the trust of followers in a leader.

To understand what may encourage or discourage EV, most of the existing research has taken a between-individual line to discover the antecedents of EV. These researchers have suggested employee characteristics such as self-esteem [27] and dispositional factors [28] as important pointers of EV. However, a comparatively ignored aspect is the possible effect of TIL on the EV and the mediation effect of TIL in the relationship between leaders' BI and the EV. Furthermore, even when EV is positively aimed to challenge the work-related status quo, it may be seen as an implicit disparagement of leaders and prove to be harmful for the employees [18]. Finally, EV is a voluntary comportment not included in formal job descriptions [29]. In this context, even highly motivated employees tend to speak up only if they trust that their leaders will consider their ideas positively and will try to implement them [30]. The quality of dyadic social exchange with the leader is based on employees' commitment and belief in the good intentions of their leader towards them. TIL has been a significant outcome built by leaders' BI [9]. Zhu et al. (2013) argued that followers' trust and respect are the key components that appear as a result of a high BI of leaders [21]. Several scholars, including Podsakoff et al. (1990), also suggest a positive relationship between leader's BI and TIL [31]. Summarizing 13 empirical studies, the meta-analysis of Dirks and Ferrin (2002) shows a correlation between leader's BI and TIL [32].

As discussed earlier, leaders' BI can be considered as a natural starting point for an examination of $\mathrm{EV}$, and our previous proposition of the relationship between leader's BI and EV is made more comprehensive by adding the mediation role of TIL in this relationship. Recently, Peng and Wei (2020) also advocate for the importance of investigating the mediating effects of TIL in this relationship [13]. In line with this proposition, this study includes the mediating role of TIL in the relationship between leaders' BI and EV. The hypotheses for mediation of TIL are presented as below:

Hypothesis 5 (H5). Leaders' BI will have a direct positive relationship with TIL.

Hypothesis 6 (H6). TIL will have a direct positive relationship with EV.

Hypothesis 7 (H7). TIL is a mediator between Leaders' BI and EV.

Figure 1 summarizes the hypotheses, showing all paths in our proposed conceptual model for empirical testing. 


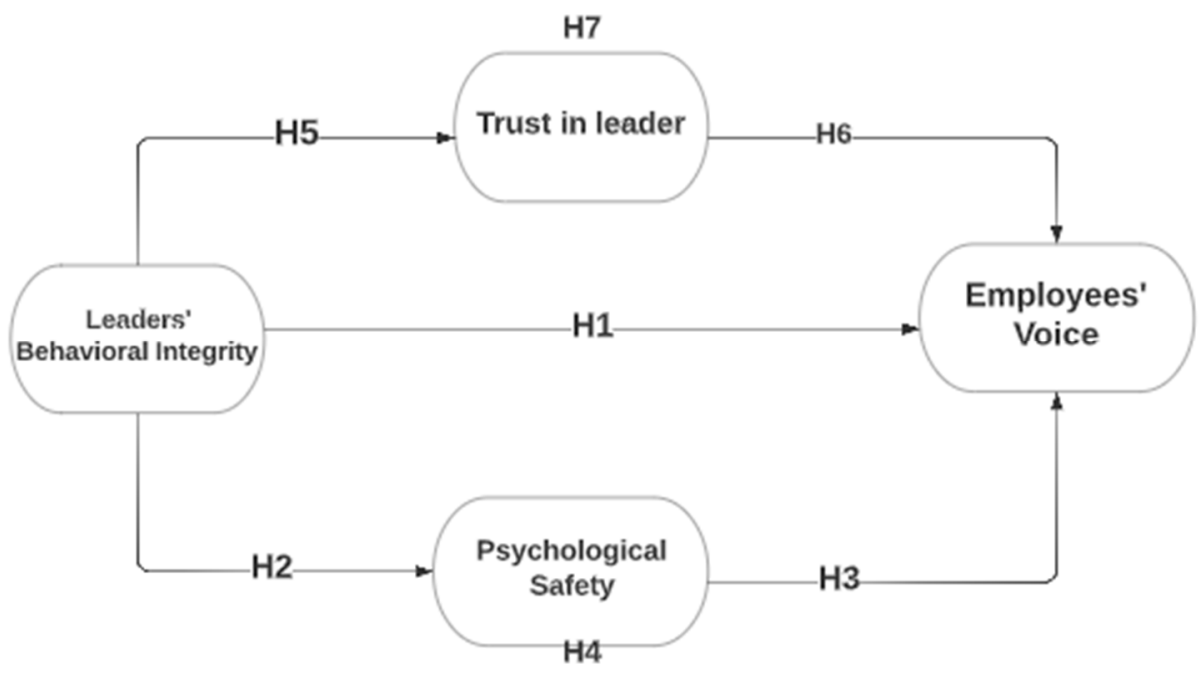

Figure 1. Conceptual model.

\section{Materials and Methods}

\subsection{Sample and Data}

Quantitative research approach was applied to test the empirical model. Data were collected through survey method at one point in time, and items of the questionnaire were adopted from previously conducted studies. Questionnaire used in this study was in English. Questionnaire was divided into two parts one included items related to demographic data, and the other parts had items related to the variables used in this study. Individual employees working in Banking Sector of Pakistan were focused on as the unit of analysis. This sector was selected since the banking sector in Pakistan has picked up pace and growing drastically. Consequently, employees are expected to be facing multiple PS-related issues [33]. Five private banks were selected for the data collection. Data was collected from the branches of three main cities of Punjab area, namely, Sialkot, Gujranwala, and Lahore, Pakistan. A non-probability sampling method, i.e., purposive sampling technique, was used. Literature recommends that this technique may be used when the researcher has identified a problem and the target audience is expected to provide relevant information [34]. Another benefit of using this technique is its simplicity in use and cost effectiveness as compared to probability sampling techniques [35]. Several past studies have endorsed this technique based on the above benefits [36]. Data were collected from employees who were working at the middle level and at the front-line. Permission was obtained from the bank mangers before disseminating the questionnaire and the purpose of the research was well explained to the respondents. One of the authors of this study explained the purpose of the survey and assured the participants of anonymity before they could respond to the questions. Questionnaires were distributed among 400 employees and out of which 384 questionnaires were received from respondents at one point in time (96\% response rate). In the first screening process 16 questionnaires were eliminated since the data was missing and the questionnaires were not complete.

\subsection{Measures}

Questionnaire was developed using previously tested scales used by past relevant studies. For instance, to measure leaders' BI, six items were used from the instrument developed by Moorman, Darnold and Priesemuth (2013) ("My Manager says he/she will do something, he/she will") [37]. The Cronbach alpha reliability for this scale was found to be 0.97 . In this study, the employees rated their manager/leader using a five-point Likert scale. To measure EV, four items from the study of Van Dyne and LePine were used ("I speak up and encourage others to get involved in issues that affect the work group") [11]. The Cronbach's alpha reliability value for this scale was 0.952 . Mediating Variable Psychological Safety was measured by six-point items adopted from study of 
Edmondson ("If you make a mistake in your organization, it is often held against you") [1]. This scale was also reliable, having a Cronbach's alpha reliability value of 0.9444 . Another mediating variable the TIL was measured by 10-point items adopted from the research paper of McAllister ("I can talk freely to my Manager about difficulties I am having at work and know that (s)he will want to listen") [38]. The reliability value of this variable was 0.98 . In all the above-mentioned variables, a five-point Likert scale was used to collect responses. Structural Equation Modelling (SEM) through Smart PLS3 was used to analyse the quantitative data.

\subsection{Demographic Data}

The demographic data include information on the personal profiles of the respondents based on gender, age, designation, and length of service. There were $81.5 \%$ male and $18.5 \%$ female respondents in the final sample. The respondents are categorized into six groups with respect to age, starting from the group of 20-25 years of age to the group of 46 and above years of age. Majority of respondents fall in the first two groups, i.e., 20-25 years and 26-30 years. In terms of designation, the respondents include Officers from six different designation levels, i.e., in an ascending order starting from 'Officer-Grade-IV' (OG-IV) to Senior Vice President (SVP) and above. Moreover, $68 \%$ of the respondents belong to OG-IV to OG-III in the sample. In terms of length of tenure, the sample is divided into five categories ranging from ' 0 to 5 years' of service to 'more than 20 years' of service. Majority of respondents, i.e., $30 \%$ of the sample, had total length of service ranging from 0 to 5 years. Monthly Income was categorized into six categories ranging from 'Rs. 15,000 to Rs. 30,000' to 'Rs. 150,001 and above'. A total of $38 \%$ of the respondents had monthly income between Rs. 30,001 to Rs. 45,000. The details of the demographic characteristics are presented in Table 1.

Table 1. Demographic characteristics of respondents.

\begin{tabular}{|c|c|c|c|}
\hline & Demographics & Frequency & Percentage \\
\hline \multirow[t]{2}{*}{ Gender } & Male & 313 & 81.5 \\
\hline & Female & 71 & 18.5 \\
\hline \multirow{6}{*}{ Age } & 20-25 Years & 138 & 36 \\
\hline & $26-30$ Years & 123 & 32 \\
\hline & 31-35 Years & 35 & 9 \\
\hline & $36-40$ Years & 58 & 15 \\
\hline & $41-45$ Years & 23 & 6 \\
\hline & 46 Years and Above & 8 & 2 \\
\hline \multirow[t]{6}{*}{ Designation } & OG IV—OGIII & 261 & 68 \\
\hline & OG-II & 58 & 15 \\
\hline & OG-I & 23 & 6 \\
\hline & AVP & 23 & 6 \\
\hline & $\mathrm{VP}$ & 12 & 3 \\
\hline & SVP and Above & 8 & 2 \\
\hline \multirow{5}{*}{ Length of service } & 0 Up to 5 Years & 115 & 30 \\
\hline & 5 Up to 10 Years & 81 & 21 \\
\hline & 10 Up to 15 Years & 58 & 15 \\
\hline & 15 Up to 20 Years & 61 & 16 \\
\hline & More than 20 Years & 69 & 18 \\
\hline \multirow{6}{*}{ Monthly Income } & Rs. 15,000 to Rs. 30,000 & 27 & 7 \\
\hline & Rs. 30,001 to Rs. 45,000 & 146 & 38 \\
\hline & Rs. 45,001 to Rs. 70,000 & 77 & 20 \\
\hline & Rs. 70,001 to Rs. 100,000 & 58 & 15 \\
\hline & Rs. 100,001 to Rs. 150,000 & 54 & 14 \\
\hline & Rs. 150,001 and Above & 23 & 6 \\
\hline
\end{tabular}

Since the data were collected through a self-reported questionnaire from the respondents at one point in time, thus, there are chances that common method bias may occur. A drawback of common method bias is that it inflates the relationship between the variables. 
To control the common method bias, we assured the respondents of the anonymity of the response. Before the distribution of questionnaire, the respondents were taken into confidence that their names will not be asked or disclosed. The respondents were also educated that there is no right or wrong answer in the response, they just need to honestly fill the questionnaire. The Harman's Single-Factor method was applied by loading all the items of the construct in the single factor with an un-rotated factor solution. The result showed a $38 \%$ variance, which was less than the recommended $50 \%$, hence proving the absence of common method bias [39,40].

\section{Results}

\subsection{Assessment of Measurement Model}

The measurement model was assessed through PLS-SEM. As a first step, the reliability and validity of measurement model was assessed. The reliability of the construct was measured through Cronbach's Alpha and Composite reliability, and the validity was measured through Convergent and Discriminant Validity. To measure the Convergent Validity, the Average Variance Extracted (AVE) and Outer Loading of the items were examined. The Fornell-Larcker Criterion and Cross Loading Values were examined to measure the Discriminant Validity, which is defined as the degree to which one construct can be differentiated from the other construct.

The measurement of the internal consistency and reliability of the instruments is primarily important, as the instruments used for the data collection must be reliable in terms of the items involved in it. For the purpose of measuring reliability, the Cronbach's alpha and composite reliability of all the instruments has been calculated. All the Instruments should have a Cronbach's alpha value higher than 0.70, as per Cortina (1993) [41]. In the present study, all the instruments used were reliable, as shown in Table 2. The values of the composite reliability are also shown in Table 2, and they are also greater than the minimum threshold of 0.70 [42].

Table 2. Convergent validity (outer loadings of items).

\begin{tabular}{ccccc}
\hline Factor Loadings & $\begin{array}{c}\text { Cronbach's } \\
\text { Alpha }\end{array}$ & $\begin{array}{c}\text { Composite } \\
\text { Reliability }\end{array}$ & AVE \\
\hline EV & & & \\
EV1 & 0.916 & & \\
EV2 & 0.921 & 0.952 & 0.906 \\
EV4 & 0.897 & & \\
EV5 & 0.850 & & \\
EV6 & 0.891 & & \\
LBI & 0.908 & & \\
\hline LBI1 & & & \\
LBI2 & 0.917 & & \\
LBI3 & 0.927 & & \\
LBI4 & 0.940 & & \\
LBI5 & 0.945 & & \\
LBI6 & 0.929 & & \\
\hline PS & 0.939 & & \\
\hline PS1 & & & \\
PS2 & 0.913 & & \\
PS3 & 0.815 & & \\
PS4 & 0.898 & & \\
PS5 & 0.736 & & \\
PS6 & 0.887 & & \\
PS7 & 0.895 & & \\
\hline
\end{tabular}


Table 2. Cont.

\begin{tabular}{ccccc}
\hline Factor Loadings & $\begin{array}{c}\text { Cronbach's } \\
\text { Alpha }\end{array}$ & $\begin{array}{l}\text { Composite } \\
\text { Reliability }\end{array}$ & AVE \\
\hline TIL & & & \\
TIL1 & 0.925 & & \\
TIL2 & 0.935 & & \\
TIL3 & 0.923 & 0.980 & \\
TIL4 & 0.882 & & \\
TIL5 & 0.943 & & \\
TIL6 & 0.902 & & \\
TIL7 & 0.924 & & \\
TIL8 & 0.929 & & \\
TIL9 & 0.905 & & \\
TIL10 & 0.931 & & \\
\hline
\end{tabular}

Validity is measured through the Convergent and Discriminant Validity. For Convergent Validity, all the item loadings were $>0.7$, and the value of AVE can also be seen in the Table 2, which is above 0.5 , confirming that the construct converges well to explain the variance of its items, which eventually confirms the convergent validity [41]. The factor loading depicts the variance detailed by the construct on that specific factor. In SEM, the general rule to consider is that a loading values greater than 0.7 represents that the factor extracts sufficient variance from that construct [41]. To check the discriminant validity of the constructs, the method described by Fornell and Larcker (2016) was used. This method describe that squared correlation relative to the AVE must be greater than the diagonal inter-constructs of the correlation. Table 3 contains values of Correlation, and the square root of AVE values confirms that the discriminated validity is accepted [43].

Table 3. Correlation with square root of average variance extracted (AVE) at the diagonal.

\begin{tabular}{ccccc}
\hline Constructs & EV & Leader's BI & PS & TIL \\
\hline EV & $\mathbf{0 . 8 9 7}$ & & & \\
LBI & 0.689 & $\mathbf{0 . 9 3 3}$ & & \\
PS & 0.623 & 0.833 & $\mathbf{0 . 8 6 7}$ & $\mathbf{0 . 9 1 9}$ \\
TIL & 0.766 & 0.766 & 0.644 & \\
\hline
\end{tabular}

\subsection{Structural Model Evaluation}

After evaluating the measurement model and its satisfaction, the structural model was examined. This step includes the statistical test and hypothesized relationships between the constructs. Table 4 shows that $p$-values and the t-statistics are significant and indicate a positive relationship of the independent variable with the dependent variable in each case. According to Hair et al. (2017), hypotheses should be non-supported at $0.05 \%$ level of significance if their $\mathrm{t}$-values are less than the recommended range of 1.65 and their $p$-values are greater than 0.05 [44]. The $R^{2}$ ( $R$ Square) value is one of the vital criteria for the assessment of structural model in PLS-SEM technique, and the $\mathrm{R}^{2}$ value for each dependent variable of the model is significant. The model also shows that the coefficients of determination $\left(R^{2}\right)$ values are greater than 0.70 , which means a greater proportion of variance in the dependent variable is predicted from the independent variable [44]. The $\mathrm{R}^{2}$ values for Psychological Safety, TIL, and EV are $0.736,0.795$, and 0.813 , respectively. In the proposed model, the estimated values of path coefficients empirically support the direct paths and indirect paths at a significance level of 0.05. Both the Algorithm and Bootstrapping were applied through Smart PLS-3. 
Table 4. Regression coefficients for direct relationships for testing direct hypothesis.

\begin{tabular}{ccccccc}
\hline Hypothesis & Paths & $\begin{array}{c}\text { Standardized } \\
\text { Beta }\end{array}$ & SE & t-Statistics & $\begin{array}{c}\text { Confidence } \\
\text { Interval }\end{array}$ & Significance \\
\hline H1 & LBI $\rightarrow$ EV & 0.313 & 0.027 & 8.787 & $(0.17-0.45)$ & 0.000 \\
H2 & LBI $\rightarrow$ PS & 0.562 & 0.008 & 117.625 & $(0.18-0.61)$ & 0.000 \\
H3 & PS $\rightarrow$ EV & 0.344 & 0.043 & 8.278 & $(0.26-0.53)$ & 0.000 \\
H5 & LBI $\rightarrow$ TIL & 0.631 & 0.022 & 39.954 & $(0.07-0.30)$ & 0.000 \\
H6 & TIL $\rightarrow$ EV & 0.416 & 0.029 & 14.500 & $(0.45-0.69)$ & 0.000 \\
\hline
\end{tabular}

Note: Leader's Behavioral Integrity (LBI), Employees' voice (EV), Psychological Safety (PS), and Trust in Leader (TIL).

The bootstrap technique, was used to test the hypotheses with $95 \%$ confidence intervals [45]. As shown in Table 4, leader's BI has a positive impact on EV ( $\beta=0.313$, t-value $=8.787$, $p<0.05)$. Hence, $\mathrm{H} 1$ is accepted. Direct impact of LBI on PS was also observed significant in the model $(\beta=0.562$, $\mathrm{t}$-value $=13.608, p<0.05)$. This supports $\mathrm{H} 2$. The third hypothesis tests the relationship between PS and EV. The results show that PS has a positive and direct effect on EV ( $\beta=0.344$, $\mathrm{t}$-value $=8.278, p<0.05)$, thus, H3 is also supported. Similarly, $\mathrm{H} 5$ and $\mathrm{H} 6$ are also supported having stated that leaders' BI has a positive and significant impact on TIL $(\beta=0.631$, $\mathrm{t}$-value $=8.787, p<0.05)$ and TIL has a significant positive impact on EV $(\beta=0.416$, $\mathrm{t}$-value $=14.50, p<0.05)$. The paths that have PS and TIL as mediators, show positive significance coefficients and hence partial mediation is also supported in the results.

Table 5 shows the results of the mediating relationships for $\mathrm{H} 4$ and H7. These hypotheses test the mediating role of PS and TIL between leader's BI and EV. The indirect impact of the leader's BI on EV through mediation of PS and TIL are upported having significant estimates for both PS and TIL. Following Preacher and Hayes (2008), the estimates for PS (estimate $=0.193$ and $p<0.05$ ) and for TIL (estimate $=0.262$ and $p<0.05$ ) supports the hypothesized proposals. A bootstrapping test at $95 \%$ confidence interval with 5000 samples was used; the lower and upper limit and t-statistics values were also calculated. The bootstrapping results of the indirect effects are presented in Table 5 which showed significant indirect effects. As both the direct and indirect impacts are positive and significant, it supports the partial mediation. The values in Table 4; Table 5 shows support for acceptance of $\mathrm{H} 4$ and $\mathrm{H} 7$.

Table 5. Bootstrapping results for indirect effects.

\begin{tabular}{|c|c|c|c|c|c|c|c|}
\hline \multirow[t]{2}{*}{ Hypothesis } & \multirow[t]{2}{*}{ Paths } & \multirow{2}{*}{ Indirect Estimates } & \multirow[t]{2}{*}{ SE } & \multirow{2}{*}{ t-Statistics } & \multirow[t]{2}{*}{ Significance } & \multicolumn{2}{|c|}{$\begin{array}{l}\text { Bootstrapping } \\
\text { 95\% Confidence Interval }\end{array}$} \\
\hline & & & & & & Lower Limit & Upper Limit \\
\hline $\mathrm{H} 4$ & $\mathrm{LBI} \rightarrow \mathrm{PS} \rightarrow \mathrm{EV}$ & 0.193 & 0.040 & 8.282 & 0.000 & 0.45 & 0.68 \\
\hline H7 & $\mathrm{LBI} \rightarrow \mathrm{TIL} \rightarrow \mathrm{EV}$ & 0.262 & 0.027 & 13.958 & 0.000 & 0.07 & 0.53 \\
\hline
\end{tabular}

\section{Discussions and Conclusions}

The aim of the study was to analyse and evaluate the relationship between leader's BI and EV with the mediating factors that have major impact on the employees such as PS and TIL. The result of the study reveals that there is a positive relationship between leader's BI and EV. The findings of the study support the leader's role in helping employees to raise their voices in the best interest of the organization [13]. In line with the indications of recent literature, our result empirically supports that the leaders BI has a positive impact on EV $[46,47]$. A significant impact between leader's BI and EV continues to be significant when PS mediates this relationship. The findings endorse the preposition that a high BI of a leader boosts the confidence employees to speak up against the odds of fear of raising voice. This is in line with the findings of recent research [41,42]. This implies that employees who see their leader exhibiting behaviourally honest conduct are more likely to raise their voice 
on an issue that needs attention. In the banking industry employees continuously interact with large number of customers may feel a lot of psychological and mental pressure. The BI of a leader can act as a helpful factor for employees to feel safe while speaking up in the interest of organization.

Second, social psychologists have long raised a question regarding how uncertainty and risk in the organizations can affect managers and employees. Kramer (2001) suggests that in an uncertain scenario, employees need a safe and trustworthy environment to interact properly [48]. He also suggests that it is trust that puts rest to this uncertainty. The empirical findings of the present study endorse these suggestions with the findings of empirical analyses. Consequently, it can be proposed for practical implications that employees will only be able to raise their voice if they feel a sense of PS within the organization. Thus, PS and TIL are important instruments for employees to raise their concerns, when needed.

With reference to a broader perspective, these arguments are built on the discussion presented by Blau in social exchange theory [49]. Social exchange theory can perfectly explain the relationship between leaders BI and EV, where PS and TIL mediate the relationship. Thus, ethical and highly trusted behaviour by the leaders make employees comfortable to talk to them on difficult issues where opinion of employees may be different then the leaders. The empirical results support this stance by showing a significant impact of leader's BI on EV through mediation of TIL. The results are also in line with the findings of Simons et al. (2007) [50]. The benefits of TIL are not only limited to EV, but it also helps in bringing in perception of fairness and justice in the organization. Hence, it can be safely concluded that employees who perceive their leaders having a high BI are more likely to believe that their leader can be trusted for raising voice on critical issues.

The study presents several noteworthy contributions to the literature in the area of leaders BI, EV, trust and PS of employees. The mediating role of PS and TIL sheds light on the implications with reference to a social augmented environment where different factors interact with each other. The findings support the mediating role of PS and TIL in the relationship of Leader's BI and EV. Thus, the findings add to the literature by providing support to the stance that individuals having high PS are more likely to raise voice in the presence of high BI of a leader. The findings also support the mediating role of TIL in the relationship of leader's BI and employees' voice, thus highlighting important insight that individuals having high trust are more likely to raise their voice.

This study may also have some limitations that need to be acknowledged and considered in any future research pursuit in the area. One of the limitations can be that the study was restricted to private banks only. Extending the sample to public sector banks may bring in some new insights. Random sampling could yield more reliable results instead of the purposive sampling technique used in this study. Another limitation can be the sole focus of this study on the interaction between leaders and employees. The employees interact with several other parties, i.e., customers, co-workers, etc., who may also affect their EV. Therefore, future researchers can bring in additional factors that can contribute to EV. The data used for empirical analyses include more male respondents than female respondents because of the prevalent social norms in the data sample. This might have an impact on the generalization of the study. This is because males are expected to be more vocal than females at the workplace, hence, having a higher ratio of men in the study might also have an effect on the overall results.

To summarize, the study provides a comprehensive framework which can be used to understand how a leader's BI helps in encouraging EV. It is observed that whenever employees feel that their leaders exhibit the properties of being behaviourally ethical they tend to be more open in giving their opinion. The banking sector is one of the important financial sectors of the economy. The employees in banking companies have continuous interaction with the customers thus the issue of mental health of the employees is more important in this sector. A creative and productive employee is a source of motivation for other employees and is also considered to be sincere with the organization. Employees can 
only exhibit creativity and organizational citizen behaviour if they consider themselves important for the organization and perceive that the organization listens to their concerns. The empirical findings reveal similar results. The study endorses that employees are only able to give their opinion and raise their concerns when they feel high trust in leaders and psychologically safe for themselves. This safety can be in the sense of both mental and physical safety. Employees do not take a chance to express their opinion if they do not trust their leaders. Hence, it is important to create an environment where they can trust the leaders and feel safe to raise their voice when needed [51]. Employees will tend to raise their voices on such issues which will ultimately result in the betterment of the organization. Considerably, in agreement with Bogan and Dedeoglu (2017), the most important theoretical contribution of our study is that it confirms the relationship between leaders' BI and EV within the scope of the banking industry [52]. The study also implies that to support the EV, training leaders about the significance of BI, PS, TIL, and EV would be helpful.

Author Contributions: Conceptualization by M.J. and A.N.; methodology by A.N.; software run by M.J.; validation by H.H. and M.H.; formal analysis, H.H.; investigation by M.H.; resources by Y.H.; writing—original draft preparation, A.N.; writing—review and editing by Y.H. and M.J. All authors have read and agreed to the published version of the manuscript.

Funding: The APC was funded by JSPS KAKENHI grant number 18K01746.

Institutional Review Board Statement: The study was conducted according to the guidelines of the departmental committee of professional ethics of FAST, School of Management, National University Lahore, Pakistan. Approval dated 20 April 2021.

Informed Consent Statement: Informed consent was obtained from all subjects involved in the study.

Conflicts of Interest: The authors declare no conflict of interest.

\section{References}

1. Edmondson, A. Psychological Safety and Learning Behavior in Work Teams. Adm. Sci. Q. 1999, 44, 350-383. [CrossRef]

2. Simons, T. Behavioral Integrity: The Perceived Alignment between Managers' Words and Deeds as a Research Focus. Organ. Sci. 2002, 13, 18-35. [CrossRef]

3. Holmes, W.T.; Parker, M.A. The relationship between behavioural integrity, competence, goodwill, trustworthiness, and motivating language of a principal. Sch. Leadersh. Manag. 2017, 38, 435-456. [CrossRef]

4. Mayer, R.C.; Davis, J.H.; Schoorman, F.D. Model of Trust Theory. Acad. Manag. Rev. 1995, 20, 709-734. [CrossRef]

5. Bass, B.M.; Steidlmeier, P. Ethics, character, and authentic transformational leadership behavior. Leadersh. Q. 1999, 10, 181-217. [CrossRef]

6. Farrell, D. Exit, Voice, Negkct Job Loyalty, as Responses Dissatisfaction: Multidimensional Scaling. Acad. Manag. J. 1983, 26, 596-607.

7. Palanski, M.E.; Kahai, S.S.; Yammarino, F.J. Team Virtues and Performance: An Examination of Transparency, Behavioral Integrity, and Trust. J. Bus. Ethic. 2010, 99, 201-216. [CrossRef]

8. Morrison, E.W. Employee Voice Behavior: Integration and Directions for Future Research. Acad. Manag. Ann. 2011, 5, 373-412. [CrossRef]

9. Way, S.A.; Simons, T.; Leroy, H.; Tuleja, E.A. What is in it for Me? Middle Manager Behavioral Integrity and Performance. J. Bus. Ethic. 2016, 150, 765-777. [CrossRef]

10. McCabe, D.M.; Lewin, D. Employee Voice: A Human Resource Management Perspective. Calif. Manag. Rev. 1992, 34, 112-123. [CrossRef]

11. Van Dyne, L.; Lepine, J.A. Helping and voice extra-role behaviors: Evidence of construct and predictive validity. Acad. Manag. J. 1998, 41, 108-119. [CrossRef]

12. Morrison, E.W. Employee Voice and Silence. Annu. Rev. Organ. Psychol. Organ. Behav. 2014, 1, 173-197. [CrossRef]

13. Peng, H.; Wei, F. How and When Does Leader Behavioral Integrity Influence Employee Voice? The Roles of Team Independence Climate and Corporate Ethical Values. J. Bus. Ethic. 2019, 166, 505-521. [CrossRef]

14. White, D.W.; Lean, E. The Impact of Perceived Leader Integrity on Subordinates in a Work Team Environment. J. Bus. Ethic. 2007, 81, 765-778. [CrossRef]

15. Elsetouhi, A.M.; Hammad, A.A.; Nagm, A.-E.A.; Elbaz, A. Perceived leader behavioral integrity and employee voice in SMEs travel agents: The mediating role of empowering leader behaviors. Tour. Manag. 2018, 65, 100-115. [CrossRef]

16. Davis, A.L.; Rothstein, H.R. The Effects of the Perceived Behavioral Integrity of Managers on Employee Attitudes: A Meta-analysis. J. Bus. Ethic. 2006, 67, 407-419. [CrossRef] 
17. Wilkinson, A.; Gollan, P.J.; Kalfa, S.; Xu, Y. Voices unheard: Employee voice in the new century. Int. J. Hum. Resour. Manag. 2016, 29, 711-724. [CrossRef]

18. Milliken, F.J.; Morrison, E.W.; Hewlin, P.F. An exploratory study of employee silence: Issues that employees don't communicate upward and why. J. Manag. Stud. 2003, 40, 1453-1476. [CrossRef]

19. Takeuchi, R.; Chen, Z.; Cheung, S.Y. Applying uncertainty management theory to employee voice behavior: An integrative investigation. Pers. Psychol. 2012, 65, 283-323. [CrossRef]

20. Detert, J.R.; Treviño, L.K. Speaking Up to Higher-Ups: How Supervisors and Skip-Level Leaders Influence Employee Voice. Organ. Sci. 2010, 21, 249-270. [CrossRef]

21. Liu, W.; Zhu, R.; Yang, Y. I warn you because I like you: Voice behavior, employee identifications, and transformational leadership. Leadersh. Q. 2010, 21, 189-202. [CrossRef]

22. Wang, Y.; Ahmad, W.; Arshad, M.; Yin, H.; Ahmed, B.; Ali, Z. Impact of Coordination, Psychological Safety, and Job Security on Employees' Performance: The Moderating Role of Coercive Pressure. Sustainability 2021, 13, 3175. [CrossRef]

23. Lee, W.; Choi, S.; Kang, S.-W. How Leaders' Positive Feedback Influences Employees' Innovative Behavior: The Mediating Role of Voice Behavior and Job Autonomy. Sustainability 2021, 13, 1901. [CrossRef]

24. Cropanzano, R.; Howes, J.C.; Grandey, A.A.; Toth, P. The relationship of organizational politics and support to work behaviors, attitudes, and stress. J. Organ. Behav. 1997, 18, 159-180. [CrossRef]

25. Simpson, J. Psychological Foundations of Trust. Curr. Dir. Psychol. Sci. 2007, 16, 264-268. [CrossRef]

26. Breuer, C.; Hüffmeier, J.; Hertel, G. Does trust matter more in virtual teams? A meta-analysis of trust and team effectiveness considering virtuality and documentation as moderators. J. Appl. Psychol. 2016, 101, 1151-1177. [CrossRef]

27. LePine, J.A.; Van Dyne, L. Predicting voice behavior in work groups. J. Appl. Psychol. 1998, 83, 853-868. [CrossRef]

28. LePine, J.A.; Van Dyne, L. Voice and cooperative behavior as contrasting forms of contextual performance: Evidence of differential relationships with Big Five personality characteristics and cognitive ability. J. Appl. Psychol. 2001, 86, 326-336. [CrossRef] [PubMed]

29. Vandewalle, D.; Van Dyne, L.; Kostova, T. Psychological Ownership: An Empirical Examination of its Consequences. Group Organ. Manag. 1995, 20, 210-226. [CrossRef]

30. Liu, W.; Tangirala, S.; Ramanujam, R. The relational antecedents of voice targeted at different leaders. J. Appl. Psychol. 2013, 98, 841-851. [CrossRef]

31. Podsakoff, P.M.; MacKenzie, S.B.; Moorman, R.H.; Fetter, R. Transformational leader behaviors and their effects on followers' trust in leader, satisfaction, and organizational citizenship behaviors. Leadersh. Q. 1990, 1, 107-142. [CrossRef]

32. Dirks, K.T.; Ferrin, D.L. Trust in leadership: Meta-analytic findings and implications for research and practice. J. Appl. Psychol. 2002, 87, 611-628. [CrossRef]

33. Asrar-Ul-Haq, M.; Kuchinke, K.P. Impact of leadership styles on employees' attitude towards their leader and performance: Empirical evidence from Pakistani banks. Futur. Bus. J. 2016, 2, 54-64. [CrossRef]

34. Sekaran, U.; Bougie, R. Research Methods for Business: A Skill-Building Approach; John Wiley \& Sons: Hoboken, NJ, USA, 2019.

35. Bagozzi, R.P.; Yi, Y. Specification, evaluation, and interpretation of structural equation models. J. Acad. Mark. Sci. 2011, 40, 8-34. [CrossRef]

36. Abu Zayyad, H.M.; Obeidat, Z.M.; Alshurideh, M.T.; Abuhashesh, M.; Maqableh, M.; Masa'Deh, R. Corporate social responsibility and patronage intentions: The mediating effect of brand credibility. J. Mark. Commun. 2020, 27, 510-533. [CrossRef]

37. Moorman, R.H.; Darnold, T.C.; Priesemuth, M. Perceived leader integrity: Supporting the construct validity and utility of a multi-dimensional measure in two samples. Leadersh. Q. 2013, 24, 427-444. [CrossRef]

38. McAllister, D.J. Affect- and Cognition-Based Trust as Foundations for Interpersonal Cooperation in Organizations. Acad. Manag. J. 1995, 38, 24-59. [CrossRef]

39. Podsakoff, P.M.; MacKenzie, S.B.; Lee, J.-Y.; Podsakoff, N.P. Common method biases in behavioral research: A critical review of the literature and recommended remedies. J. Appl. Psychol. 2003, 88, 879-903. [CrossRef] [PubMed]

40. Kock, N. Common Method Bias in PLS-SEM. Int. J. e-Collab. 2015, 11, 1-10. [CrossRef]

41. Cortina, J.M. What is coefficient alpha? An examination of theory and applications. J. Appl. Psychol. 1993, 78, 98-104. [CrossRef]

42. Qing, M.; Asif, M.; Hussain, A.; Jameel, A. Exploring the impact of ethical leadership on job satisfaction and organizational commitment in public sector organizations: The mediating role of psychological empowerment. Rev. Manag. Sci. 2019, 14, 1405-1432. [CrossRef]

43. Fornell, C.; Larcker, D.F. Evaluating structural equation models with unobservable variables and measurement error. J. Mark. Res. 2016, 18, 39-50. [CrossRef]

44. Hair, J.; Hollingsworth, C.L.; Randolph, A.B.; Chong, A.Y.L. An updated and expanded assessment of PLS-SEM in information systems research. Ind. Manag. Data Syst. 2017, 117, 442-458. [CrossRef]

45. Efron, B. The Bootstrap and Modern Statistics. J. Am. Stat. Assoc. 2000, 95, 1293-1296. [CrossRef]

46. Elsaied, M.M. Supportive leadership, proactive personality and employee voice behavior. Am. J. Bus. 2019, 34, 2-18. [CrossRef]

47. Liu, S.-M.; Liao, J.-Q.; Wei, H. Authentic Leadership and Whistleblowing: Mediating Roles of Psychological Safety and Personal Identification. J. Bus. Ethic. 2015, 131, 107-119. [CrossRef]

48. Kramer, R.M. Trust Rules for Trust Dilemmas: How Decision Makers Think and Act in the Shadow of Doubt. Lect. Notes Artif. Intell. 2001, 2246, 9-26. [CrossRef] 
49. Blau, P.M. Exchange and Power in Social Life. Exch. Power Soc. Life 2017. [CrossRef]

50. Simons, T.; Friedman, R.; Liu, L.A.; Parks, J.M. Racial differences in sensitivity to behavioral integrity: Attitudinal consequences, in-group effects, and "trickle down" among Black and non-Black employees. J. Appl. Psychol. 2007, 92, 650-665. [CrossRef]

51. Asif, M.; Miao, Q.; Jameel, A.; Manzoor, F.; Hussain, A. How ethical leadership influence employee creativity: A parallel multiple mediation model. Curr. Psychol. 2020, 1-17. [CrossRef]

52. Boğan, E.; Dedeoğlu, B.B. The Effects of Perceived Behavioral Integrity of Supervisors on Employee Outcomes: Moderating Effects of Tenure. J. Hosp. Mark. Manag. 2017, 26, 511-531. [CrossRef] 